\title{
MAXILLARY TEETH EXTRACTION WITHOUT A PALATAL INJECTION: A RANDOMIZED CONTROL TRIAL
}

\author{
Mohammad Abdelhamied Shuman*
}

\begin{abstract}
Purpose: The aim of this research was to assess the clinical effectiveness of buccal infiltration of $4 \%$ Articaine hydrochloride in comparison to routine buccal and palatal infiltration during the extraction of maxillary molars.

Patients and Methods: Current research were carried out on 200 patients where study group included 100 patients, and 100 were controls. Unilateral extractions were made to patients in the research group. All patients were injected with $1.8 \mathrm{ml}$ of $4 \%$ Articaine hydrochloride with 1:100.000 epinephrine in the buccal vestibule of chosen tooth for removal without performing palatal injection. The maxillary tooth was removed after 8 minutes. One hundred participants in the control group were subject to the same procedure with palatal injection. Upon extracting, every patient completed a face pain scale (FPS) and visual analog scale (VAS).
\end{abstract}

Results: According to the FPS and VAS scores, the difference in pain rates was statistically non-significant $(p>0.05)$ when compared with permanent maxillary dental removal with or without palatal injection.

Conclusion: Permanent maxillary tooth extraction is possible when $1.8 \mathrm{~mL}$ of $4 \%$ Articaine is deposited in the buccal vestibule of the tooth without palatal anesthesia.

KEY WORDS: Articaine 4\%, pain, palatal injection.

\section{INTRODUCTION}

Fear and behaviors linked to anxiety have been known as a significant impediment to dental involvement ${ }^{(1)}$. The main explanation for many dental operations is outstanding local anesthesia. The painless procedure not only adds to the patient's benefit, but also helps to treat the patient peacefully and without haste ${ }^{(2)}$. Exodontia is one of the important procedures carried out in oral surgery. In everyday practice, maxillary molars are required to be extracted for various reasons, like orthodontic treatment, unrestorable caries, apical pathologies, severe periodontitis and for prophylactic reasons. Palatal injection induces typically discomfort for permanent maxillary dental extraction including pain during injection, sensation of pressure and soft palate numbness. Palatal injection is considered as

\footnotetext{
* Oral and Maxillofacial Surgery Faculty of Dentistry Al-Azhar University Assiut Branch.
} 
the most painful among all oral cavity injections ${ }^{(3)}$. Administering palatal anesthesia is considered one of the most painful dentistry treatments, and it is recognized as the primary explanation for fear of oral involvement. Several studies indicate that the majority of patients are poorly handled in palatal injections ${ }^{(4)}$. Palatal injections also are associated with some pain because palatal mucosa is strongly attached to the bone and palatal mucosa is strongly intertwined ${ }^{(5)}$. Consequently, many procedures have been recommended to decrease pain caused by palatal injections. The most commonly used is the application of Eutectic Mixture of Local Anesthetics (EMLA) topical anesthetics prior to the injection ${ }^{(6)}$. Even though other methods like, pressure administration, Computer Controlled Local Anesthesia Delivery Systems (CCLADS), palate topical cooling, and Transcutaneous Electrical Nerve Stimulation (TENS) are mentioned in the literature but it is not universally accepted ${ }^{(7-12)}$. Researches claimed that Articaine obviated the need for routine palatal injections on account of its better diffusion throughout hard and soft tissues than other local anesthetic agents ${ }^{(13)}$. Current study aims to assess the clinical efficacy of buccal infiltration of $4 \%$ Articaine hydrochloride in comparison to routine buccal and palatal infiltration during the extraction of maxillary molars.

\section{PATIENTS AND METHOD}

A potential, randomized, double blind study to compare the effectiveness of Articaine hydrochloride (4\%) with 1:100,000 epinephrine (ARTINIBSA $40 \mathrm{mg} / 0.01 \mathrm{mg} / \mathrm{ml}$ ) ${ }^{\circledR}$ (Fig.1) was performed in permanent maxillary teeth extraction while injected with single buccal infiltration versus regular palatal and buccal injections. Two hundred adults recruited from patients referred to Department of Oral and Maxillofacial Surgery faculty of dental medicine for Boys Al-Azhar University for extraction of permanent maxillary molars, were enrolled in this study. Recruitment was attempted by experienced clinicians not involved in the research. The criteria for inclusion was based upon a medical history questionnaire, which allowed patients age between 15 and 50 years old and in good health to included. Exclusion of patients with sensitivity to Articaine, drugs that may impact anesthetic evaluations, patients with pathology in injection area, teeth that involved surgical extraction procedures or had any contraindications for tooth extraction. The Ethics and Research Committee of Oral and Maxillofacial Surgery department, Faculty of Dental Medicine for Boys Al-Azhar University had adopted current research.

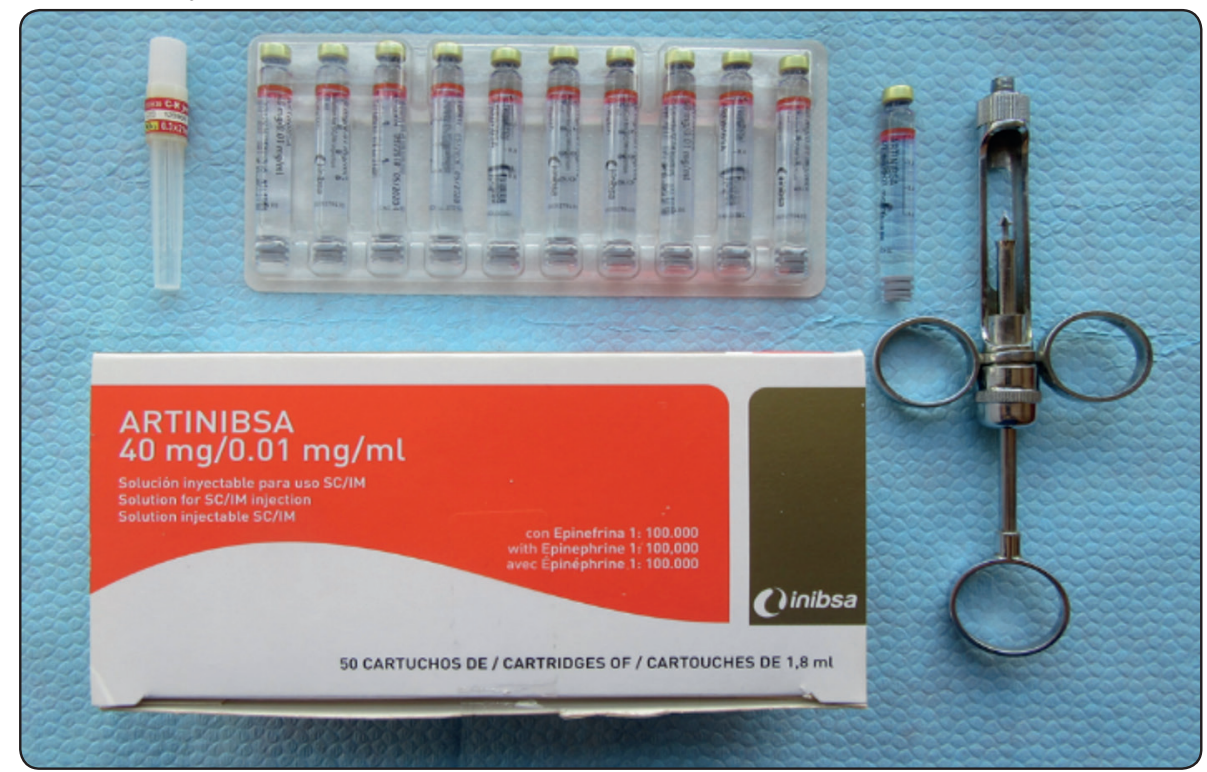

Fig. (1) Local Anesthetic Kit 
The 200 participant patients were divided into two groups: (1) study group and (2) control group, with 100 patient each. The participants were allocated into the particular groups randomly using a toss random number. Study group (group 1) comprised 100 patients, 66 males and 34 females, average age 36.4 years. In this group $1.8 \mathrm{~mL}$ of $4 \%$ Articaine hydrochloride with 1:100.000 epinephrine was injected only into the buccal vestibule close to the targeted tooth according to the conventional method without palatal injection under aseptic conditions.

Another 100 patients of control group (group 2), 58 male and 42 females with mean age 34.6 years, were injected buccally with $1.5 \mathrm{~mL} 4 \%$ Articaine hydrochloride with 1:100.000 epinephrine by an identical protocol and $0.3 \mathrm{~mL}$ injected by palatal infiltration under a septic condition.

Each patient was given an explanation concerning the tools for pain intensity measurements before starting the extraction procedures. The patients demonstrated the level of pain by correlating the perceived amount of pain using the $100-\mathrm{mm}$ visual analogue scale (VAS), on each end of were "no pain" and "absolute pain". Furthermore, the facial pain scale (FPS) contains a scale of eleven-points (between 0 and 10) numerical scale expressing pain from "no pain" to "worst imaginable pain"; respectively ${ }^{(14)}$. FPS interprets perceived pain using the expressions or actions experiences when the patient cannot articulate the severity of his or her pain ${ }^{(15)}$. The local anesthetic procedure in all the patients was attempted by the same operator. To confirm blinding, the operator who administered the anesthesia and the other who performed the extraction of the tooth not involved with recording the trial outcomes. The tooth was extracted with a routine maneuver, with least manipulation of palatal tissue. Each patient has been regularly tested for pain severity (FPS) by an independent observer, also asked about pain intensity experienced on a (VAS) after tooth extraction and the scores were recorded $^{(16)}$ (Fig.2).

\section{Statistical Assessment}

Statistical analyses were performed to assess the difference between group-1 (test group) and the group-2 (control group). Difference in pain scores between two groups were assessed statistically by inferential statistics by Welch's $t$ test at 0.05 level of significance All statistical analyses were carried out using IBM-SPSS package version 23.0 for Mac OS.

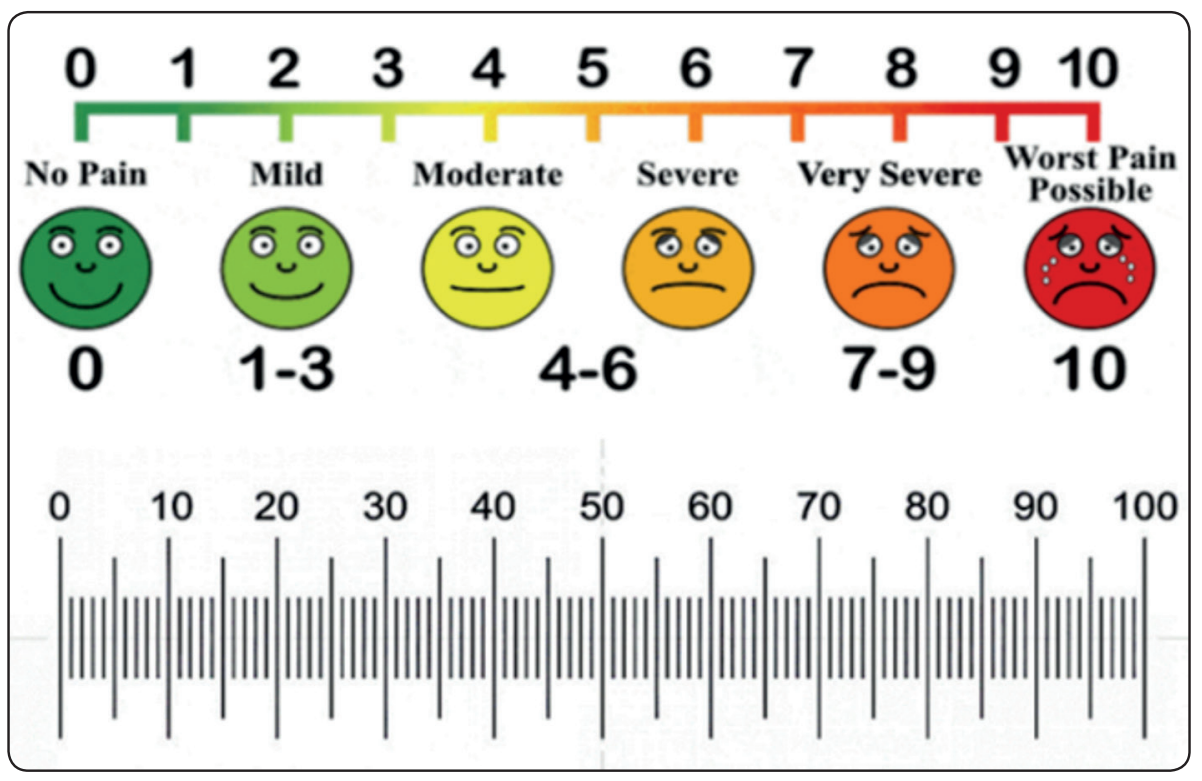

Fig. (2) Faces Pain Scale and Visual Analogue 


\section{RESULTS}

In this study the pain induced during extraction of maxillary molars with or without palatal injection were compared by using two parameters for pain measuring scores VAS \& FPS (Figures 3 and 4). All the patients in both groups well tolerated the whole procedure of the molar extractions without recording a severe pain and they described it as it was a painless or too slightly discomfort procedure. Pain scores were analyzed statistically and represented as mean, standard deviation (SD), and standard error, differences between group 1 and group 2 were assessed using Welch's t test for both variables of both groups. It was revealed that there was no significant difference between both groups (Welch's t-test; $p$-value> 0.05). The Visual Analog Score

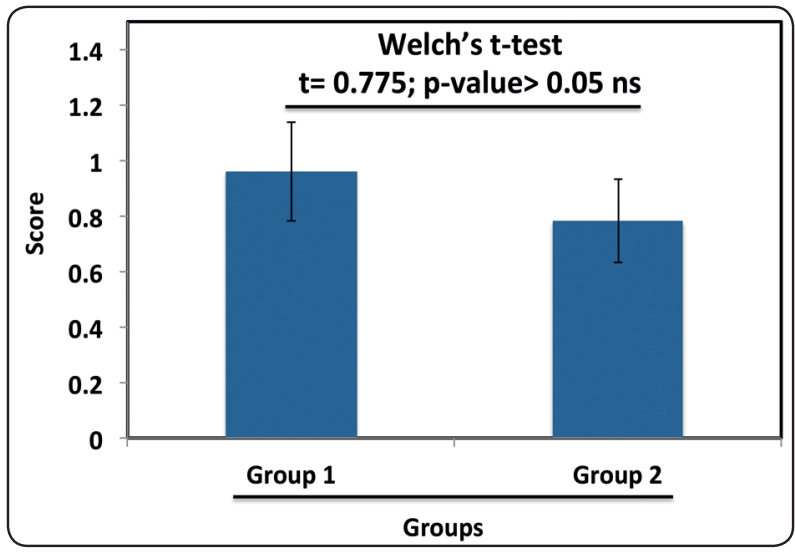

Fig. (4) Facial pain score (mean \pm SE)

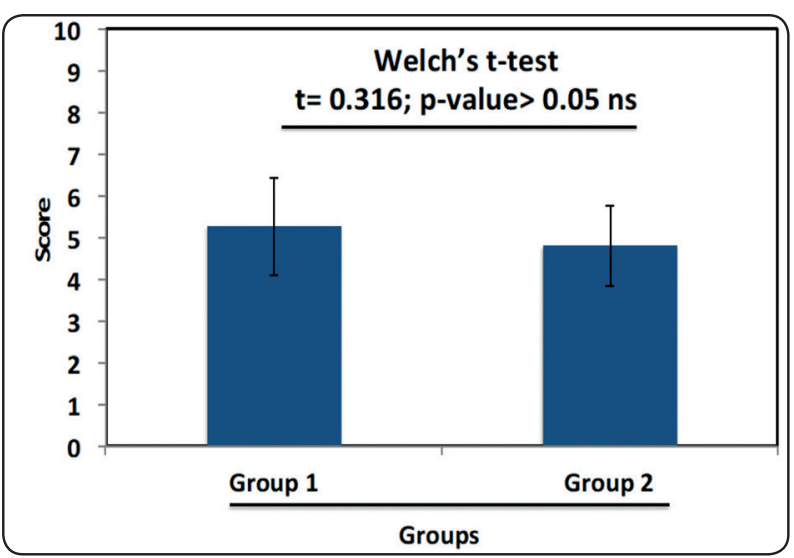

Fig. (3) Facial analog score (mean \pm SE)
(VAS) of group-1 and group-2 showed an average $( \pm \mathrm{SD})$ of $5.28 \pm 11.7$, and $4.8 \pm 9.7$; respectively. The difference between the two groups (1 and 2) in Visual Analog Score (VAS) were non-significant as revealed by Welch's t-test ( $\mathrm{t}=0.316$; $p$-value $>0.05$ ). Furthermore, the difference between the two groups (1 and 2) in Visual Analog Score (VAS) were nonsignificant as revealed by Welch's $\mathrm{t}$-test $(\mathrm{t}=0.775$; $p$-value $>0.05$ ) (Tables 1 and 2).

TABLE (1) Visual Analog Score (VAS)

\begin{tabular}{|l|c|c|l|}
\hline & Group 1 & Group 2 & Welch's t test \\
\hline No. of patients & 100 & 100 & $\mathrm{df}=192$ \\
Mean & 5.28 & 4.80 & $\mathrm{t}$ value $=0.316$ \\
SD & 11.69 & 9.70 & P value $=0.75$ \\
SE & 1.17 & 0.97 & \\
\hline
\end{tabular}

* p-value significant at $p<0.05$

TABLE (2) Facial Pain Score (FPS)

\begin{tabular}{|l|c|c|l|}
\hline & Group 1 & Group 2 & Welch's t test \\
\hline No. of patients & 100 & 100 & $\mathrm{df}=192$ \\
Mean & 0.96 & 0.78 & $\mathrm{t}$ value $=0.775$ \\
SD & 1.78 & 1.49 & P value $=0.44$ \\
SE & 0.18 & 0.15 & \\
\hline
\end{tabular}

* p-value significant at $p<0.05$

\section{DISCUSSION}

Maxillary teeth extraction is a common procedure in Oral surgery. Separate sensory innervations of the palate have led to the routine applying of palatal anesthesia although it is painful, for maxillary molar extraction procedure ${ }^{(17,18)}$. There are many techniques have been used to reduce pain on palatal injection such as, topical pressure, topical anesthesia, topical cooling, TENS, CCLADS and papillary approach palatal anesthesia ${ }^{(19)}$. However, the number of adjunctive techniques and the different modern 
injection modalities were recommended to alleviate the palatal injection pain and discomfort, none of them have earned universal clinicians approval, some of them even time consuming, complex requiring-specific apparatus, expensive, and palatal injection is still painful and is relatively poorly tolerated by patients ${ }^{(5-10)}$. Indeed, in addition to its abundance of nerve supplies, the palatal mucosa is compact, thick, and firm to its essential periosteum, such that injections into the palate are often extremely painful ${ }^{(5)}$. This discomfort appears to be induced rather than by the needle entering mucosa due to the movement of the mucoperiosteum ${ }^{(20)}$.

It is possible to avoid the palatal injection if any local anesthetic produces palatal anesthesia when injected buccally, as buccal infiltration injections could be painless ${ }^{(2)}$. Several authors recently reported that maxillary erupted permanent molars could be extracted only by buccal infiltration anesthesia $^{(13)}$. Articaine was reported to have the ability to disperse tissues among local anesthetics, enabling palatal injection to be obviated during extraction of maxillary teeth when infiltrated orally. This is due to Articaine's chemical structure which, is different from other ester and amide local anesthetics because of the presence of thiophenic ring instead of aromatic ring, and also the presence of an additional ester ring. This provides Articaine with greater plasma protein binding, intrinsic potency as well as increased liposolubility, versus other commonly used local anesthetics. Such differential features are expressed clinically by a superior bony tissue diffusion, a shorter latency period and increased duration of anesthesia. A further clarification that, the porous nature of the maxilla enables any local anesthetic to diffuse from the buccal side to the palatal side ${ }^{(21)}$.

In this study, we had 200 patients who required unilateral maxillary molar extraction with equal distribution in both experimental and control groups to compare with. Hence, 100 patients underwent extraction without palatal injection. Results of this trial clearly demonstrate that palatal injection is not mandatory for maxillary molars extraction. Another study in 2009, also gave similar results ${ }^{(22,23)}$. It has been proved that depositing $1.7 \mathrm{ml}$ of $4 \%$ Articaine hydrochloride with 1:100,000 epinephrine into buccal vestibule delivers similar clinical effectiveness for maxillary tooth extraction as regular kind of anesthesia by palatal injection. It has been concluded that, extraction of maxillary third molar could be carried out with $4 \%$ articaine $\mathrm{HCl}$ buccal infiltration anesthesia only in majority of cases without need for palatal injection. On the other hand, in another published study, the authors could not find any evidence to confirm the hypothesis regarding the presence of anesthesia of $4 \%$ Articaine $\mathrm{HCl}$ at the palatal tissues after buccal infiltration injection $^{(24)}$. Other investigators also had similar results but their work was preliminary study with small sample size and had an unequal distribution between both the control and experimental groups unlike this study ${ }^{(25)}$. Regarding the classical knowledge, two to three minutes latency would be sufficient in buccal infiltration anesthesia ${ }^{(18)}$. This technique requires a longer latency to allow the anesthetic solution to be diffused on the palate. Similar observation was concluded that, palatal tissue is anesthetized sufficiently for extraction after diffusion from buccal infiltration with a prolonged latency period ${ }^{(13)}$. In this study, the delay observed was for 8 minutes after the buccal infiltration. Majority of the patients in this study demonstrated extraction as completely painless or with too slight faint pain.

\section{CONCLUSION}

In conclusion, a single infiltration injection of $1.8 \mathrm{~mL}$ of $4 \%$ Articaine Hydrochloride (1:100,000 epinephrine) into the target tooth buccal vestibule will enable the extraction of permanent maxillary molars without palatal injection. 


\section{REFERENCES}

1. Randall C, McNeil D, Shaffer J, Crout R, Weyant R, Marazita M. Fear of pain mediates the association between MC1R genotype and dental fear. J Dent Res. 2016;95:1132-7.

2. St George G, Morgan A, Meechan J, Moles DR, Needleman I, Ng YL, et al. Injectable local anaesthetic agents for dental anaesthesia. Cochrane Database Syst Rev. 2018;7:Cd006487.

3. Sharma U. Palatal ulceration: A local anesthetic complication. Indian J Health Sci Biomed Res. 2017;10:94-6.

4. Flanagan DF. The effectiveness of articaine in mandibular facial infiltrations. Local and regional anesthesia. 2016; 9:1-6.

5. Smolarek PdC, Wambier LM, Siqueira Silva L, Chibinski ACR. Does computerized anaesthesia reduce pain during local anaesthesia in paediatric patients for dental treatment? A systematic review and meta-analysis. Int J Paediatr Dent. 2020;30:118-35.

6. Lee HS. Recent advances in topical anesthesia. J Dent Anesth Pain Med. 2016;16:237-44.

7. Amorim KdS, Franz-Montan M, Groppo FC, Muniz BV, Araújo JSMd, Santana JVF, et al. Palatal needle-free anesthesia for upper molars extraction. A randomized clinical trial. J Craniomaxillofac Surg. 2020;5:112-8

8. Tirupathi SP, Rajasekhar S. Effect of precooling on pain during local anesthesia administration in children: a systematic review. J Dent Anesth Pain Med. 2020;20:119-27.

9. Hindocha N, Manhem F, Bäckryd E, Bågesund M. Ice versus lidocaine $5 \%$ gel for topical anaesthesia of oral mucosa - a randomized cross-over study. BMC Anesthesiology. 2019;19:227-38.

10. Rizzo-Lorenzo A, Sánchez-Torres A, Noguera-Mutlló C, Pérez-Beltrán I, Figueiredo R, Valmaseda-Castellón E. Influence of information concerning a computerized anesthesia system on dental anxiety: a randomized controlled clinical trial. Med Oral Patol Oral Cir Bucal. 2020;25:217-23.

11. Dasarraju RK, Svsg N. Comparative efficacy of three topical anesthetics on 7-11-year-old children: a randomized clinical study. J Dent Anesth Pain Med. 2020;20:29-37.

12. Madadian MA, Renton T. Local anaesthesia in dentistry - achieving effective painless injections. Dent Update. 2019;46:837-46.

13. Cui L, Zhang Z, Huang J, Yin D, Xu L. Extraction of permanent maxillary teeth without palatal injection: a meta-anal- ysis. Oral Surg Oral Med Oral Pathol Oral Radiol Endod. 2018;126:187-95.

14. Pathak A, Sharma S, Jensen MP. The utility and validity of pain intensity rating scales for use in developing countries. Pain reports. 2018;3:672-800

15. Sirintawat N, Sawang K. Pain measurement in oral and maxillofacial surgery. J Dent Anesth Pain Med. 2017;17:253-63.

16. Safikhani S, Gries KS, Trudeau JJ, Reasner D, Rüdell K, Coons SJ, et al. Response scale selection in adult pain measures: results from a literature review. J Patient Rep Outcomes. 2018;2:40-9

17. Ellis E HJ, Tucker MR. Contemporary Oral and Maxillofacial Surgery. $7^{\text {th }}$ ed ed. St Louis: Mosby; 2020.

18. Malamed SF . Handbook of Local Anesthesia. $7^{\text {th }}$ ed ed. St Louis: Mosby; 2019.

19. Gupta S, Kumar A, Sharma AK, Purohit J, Narula JS. "Sodium bicarbonate": an adjunct to painless palatal anesthesia. Oral Maxillofac Surg. 2018;22:451-5.

20. Wiswall AT, Bowles WR, Lunos S, McClanahan SB, Harris S. Palatal anesthesia: comparison of four techniques for decreasing injection discomfort. Northwest dent. 2014; 93:25-9.

21. Al-Mahalawy H, Abuohashish H, Chathoth S, Al-Masoud N, Al-Jandan B. Articaine Versus Lidocaine Concentration in the Palatal Tissues After Supraperiosteal Buccal Infiltration Anesthesia. J Oral Maxillofac Surg. 2018;76:315-22.

22. Kolli NK, Nirmala SV, Nuvvula S. The Effectiveness of Articaine and Lidocaine Single Buccal Infiltration versus Conventional Buccal and Palatal Injection Using Lidocaine during Primary Maxillary Molar Extraction: A Randomized Control Trial. Anesth Essays Res. 2017;11:160-4.

23. Kumar DP, Sharma M, Patil V, Subedar RS, Lakshmi GV, Manjunath NV. Anesthetic Efficacy of Single Buccal Infiltration of 4\% Articaine and 2\% Lignocaine in Extraction of Maxillary 1(st) Molar. Ann Maxillofac Surg. 2019;9:239-46.

24. Sharma K, Sharma A, Aseri M, Batta A, Singh V, Pilania $\mathrm{D}$, et al. Maxillary posterior teeth removal without palatal injection -truth or myth: a dilemma for oral surgeons. JCDR 2014: 8;1-4.

25. Bataineh AB, Al-Sabri GA. Extraction of Maxillary Teeth Using Articaine Without a Palatal Injection: A Comparison Between the Anterior and Posterior Regions of the Maxilla. J Oral Maxillofac Surg. 2017;75:87-91. 